\title{
Beyond barriers - A case study on driving forces for improved energy efficiency in the foundry industries in Finland, France, Germany, Italy, Poland, Spain, and Sweden
}

\author{
Patrik Thollander, Sandra Backlund, Andrea Trianni and Enrico Cagno
}

\section{Linköping University Post Print}

\section{Tweet}

N.B.: When citing this work, cite the original article.

Original Publication:

Patrik Thollander, Sandra Backlund, Andrea Trianni and Enrico Cagno, Beyond barriers - A case study on driving forces for improved energy efficiency in the foundry industries in Finland, France, Germany, Italy, Poland, Spain, and Sweden, 2013, Applied Energy, (111), 636-643.

http://dx.doi.org/10.1016/j.apenergy.2013.05.036

Copyright: Elsevier Ltd. 


\title{
Beyond barriers - A case study on driving forces for improved energy efficiency in the foundry industries in
}

\section{Finland, France, Germany, Italy, Poland, Spain, and}

\author{
Sweden \\ Patrik Thollander ${ }^{\mathrm{a}}$, Sandra Backlund ${ }^{\mathrm{a}}$, Andrea Trianni ${ }^{\mathrm{b}}$, Enrico Cagno $^{\mathrm{b}}$ \\ ${ }^{a}$ Department of Management and Engineering, Linköping University, SE-581 83 \\ Linköping, Sweden \\ ${ }^{\mathrm{b}}$ Department of Management, Economics and Industrial Engineering, Politecnico di \\ Milano, Piazza Leonardo da Vinci 32 - 20133 Milan, Italy
}

\begin{abstract}
Energy management plays an important role in the transformation of industrial energy systems towards improved energy efficiency and increased sustainability. This paper aims to study driving forces for improved energy efficiency in some European energy-intensive foundry industries. The investigation has been conducted as a multiple case study involving 65 foundries located in Finland, France, Germany, Italy, Poland, Spain, and Sweden. The most relevant perceived driving forces were found to be financially related, followed by organizational driving forces. Nevertheless, some differences can be appreciated according to the firm's size and country. Almost half of the studied foundries lack a long-term energy strategy, about one-fourth stated that they have used Energy Performance Contracting (EPC), and only approximately one in ten foundries have used Third Party Financing (TPF). Among the studied foundries, three out of five have conducted an energy audit. On average, the energy saving potential according to the respondents is stated to be $7.5 \%$. In conclusion, energy
\end{abstract}


management in the European foundry industry, despite increasing energy prices and extensive energy policy actions taken by the EU, still seems to have great improvement potential, calling for future research and policy actions in the field.

Keywords: Energy management practices; Driving forces for improved energy efficiency; Energy services; Energy audit; European foundry industry.

\section{Introduction}

Increased energy efficiency is one of the highlighted objectives in the European strategy for smart, sustainable and inclusive growth [1]. Improving energy efficiency in energy-intensive industry is thus becoming increasingly important. From an industrial perspective, improved energy efficiency is recognized as providing a number of direct economic benefits, apart from indirect benefits such as increased competitiveness and higher productivity [2], [3], [4]. Despite the existence of cost-effective energy efficiency measures (EEM) in industry, new energy efficiency technologies often remain unimplemented due to several barriers [5]. The discrepancy between what is perceived as the optimal level of energy efficiency technology and the actual implementation of energy efficiency is referred to as the "energy efficiency gap" [6].

Energy costs for European energy-intensive foundry industries represent about 5-15\% of the added value [7]. Two main means of reducing energy costs can be identified. First, enterprises can apply supply side management, e.g. through investments in new electricity production or negotiating lower prices with their energy suppliers [7-8]. Second, enterprises can apply demand side management, e.g. adopt energy management practices at plant level within four principal areas: energy-efficient technologies, load management, energy conversion, and 
encouraging more energy-efficient behaviour (energy conservation). Energy management has received increased attention in regard to policy formulation, both in the form of Long-Term Agreements (LTA) and Voluntary Agreements (VA) [9]. Moreover, standards for energy management have been set internationally, e.g. the ISO 50001. Also, recent research shows that when not only adoption of technology but energy management practices are included, the energy efficiency potential is in fact higher [10].

Previous studies of improving industrial energy efficiency have been conducted, e.g. in the area of energy audits [11-13], energy optimization [14], [15], energy modelling [16], [17], and industrial energy audit programs related to adoption of more energy-efficient technologies [18], [19], as well as research on empirical barriers to energy efficiency in energy-intensive [20-22] and non-energy-intensive industry [23]. However, research concerning actual energy management practices in industry has so far been scarce, some exceptions being [24-26]. Moreover, studies concerning energy services in industry have not been extensive, some exceptions being [27-32]. Studies on driving forces for improved energy efficiency in industry have not been extensively published either [33-37]. The noticeable lack of published research in regard to energy management and energy services, i.e., major means to overcome barriers and achieve a more energy-efficient economy, as well as the lack of studies on drivers for improved energy efficiency, calls for research in the field. The European foundry industry is of particular interest to study in this regard due to its energy intensity. Therefore, this paper aims to study energy management practices in the European foundry industry and the driving forces for improved energy efficiency. The study covers major perceived driving forces, energy management practices, deployment of energy services, and is the first study within a transnational European context, thus contributing to improve the number of published research empirical findings in this field in the European industrial sector. 


\section{Driving forces for improved energy efficiency}

Empirical studies in various industrial and public sectors have illustrated the existence of an energy efficiency gap. Energy as a resource is not being used as efficiently as it could be, and there is a recognized but still untapped reservoir of cost-effective technologies that are not being employed, even though these could substantially improve the energy end-use. This efficiency gap occurs in all sectors of society: households, public buildings, institutions and private industries [6], [31], [38], [39]. Since the foundry industry is an energy-intensive sector, this inefficient use of energy will become an increasing problem for the competitiveness of European foundries, as electricity and fuel prices are expected to increase, and those enterprises are facing the growing competition of developing countries characterized by lower labour costs.

Barrier models have been the widely accepted model for explaining the existence of the energy efficiency gap [40-41], e.g. in the new European Energy Efficiency Directive. Indeed, a crucial step to overcome the gap is represented by a deep understanding of the barriers, i.e., what economic, behavioural and organizational problems prevent industries from adopting EEMs. A number of studies have investigated barriers to energy efficiency empirically [21, 23, 34-35, 42-43]. Several studies have also investigated barriers to energy efficiency in e.g. the Swedish foundry industry [22], as well as the foundry industries in India [44], [45] and China [46], and more recently in the European context [47].

Despite the extensive amount of literature on barriers to energy efficiency, drivers for improved energy efficiency has so far received little research attention. A first contribution has been provided by de Groot et al. [33], who, analysing Dutch manufacturing enterprises, stated that cost reductions resulting from lowered energy use and direct fiscal subsidies were the two highest ranked driving forces. More recent contributions can be found in Swedish studies 
focused on non-energy-intensive manufacturing, foundry and pulp and paper industry [21-22], [34], which found that, while barriers differ among the studied sectors, the largest ranked driving forces in the three studies were, apart from cost reductions resulting from lowered energy use, people with real ambition and the existence of a long-term energy strategy. In 2010 Hasanbeigi et al. [36] performed a study in the Thai manufacturing industry, finding that the highest ranked driving force was reduced production cost. Also, Cagno and Trianni [37] found that the most important driving forces in Italian firms were investment subsidies for technology, having long-term benefits and future external pressures. Apart from the previously presented publications, two more should also be noted. Nagesha (2005) found that achieving cost reduction and enhancing competitiveness were the two top drivers, and Reddy and Gaudenz (2007) outline a taxonomy for barriers and drivers [48-49].

\section{Energy management in industry}

Energy management is widely recognized as a primary means to overcome barriers to energy efficiency. Literature has shown the relevance of both the adoption of energy-efficient technologies and more efficient routines and practices within the industrial sector [50]. Indeed, research shows that the adoption of energy management practices in industries may save up to $40 \%$ of the total energy use, half derived from energy management practices and half from investments in energy-efficient technologies [51]. Examples of successful practices to be promoted can be found in the literature, e.g. the implementation of a long-term energy strategy, thanks to top management support, has been shown to be a key driver in previous studies [22]. Moreover, top management support is recognized as crucial for the creation of an in-house energy management program. The adoption of the aforementioned practices should be done in addition to conducting an energy audit [52]. Indeed, without a picture of previous cash flows, a 
controller has difficulty making a sound economic budget. Similarly, without an energy audit and energy balance sheet, i.e., a display of where energy is used, the energy controller lacks a top-down view. This in turn creates a risk for adverse selection of measures, i.e., too heavy focus on measures which do not use much energy, or have low energy efficiency potential.

Apart from conducting an energy audit, which is heavily emphasized in the 2012 European Energy Efficiency Directive, one measure to overcome barriers and implement energy management and energy-efficient technologies is energy services. Energy services is a relatively new term that refers to contractual arrangements that aim to measurably improve energy efficiency. Apart from energy audits, an Energy Service Company (ESCO) can offer financial support in the investments in new technology [29], as well as additional services, e.g. support in managing the intervention within the plant and providing information about existing opportunities. Two common energy services are EPC and TPF. Both measures, as well as energy audits, are key means according to the European Commission to improve energy efficiency in the economy.

Energy services have been mentioned both in academic literature [5], [29], [53] and in political directives as a tool to overcome many of the barriers to energy efficiency in organizations whose core business is not related to energy. Consulting an ESCO is a way for organizations to out-source energy management. They help in overcoming informational and financial barriers since an ESCO's core business is energy management, and their services require them to stay well informed about technical and economical energy management solutions. Since ESCOs are specialized in energy savings they have the advantage of economies of scale, making use of their knowledge multiple times, thus reducing the costs for knowledge assimilation per $\mathrm{kWh}$ of improved energy efficiency. TPF helps to overcome capital shortages [5], [29], [53]. Energy services are provided in performance-based contracts, which also reduces the risk since the ESCO shares the project risk. However, consulting an external party to manage something as 
complex as an industrial energy system also implies transaction costs. What an ESCO gains in scale advantage and reduced risk must be compensated for by the extra costs generated from transferring some or all of the responsibility for energy management to an external party. Since transaction costs are not necessarily related to the size of the contract, this results in complex energy services being more profitable in large contracts [29], [37], [53].

\section{Methods and delimitations}

Within a wider scope of getting a broader picture of the foundry sector in several European countries, i.e., Finland, France, Germany, Italy, Poland, Spain, and Sweden, the explorative nature of the study and the multiple sites investigated drove this study to be carried out as a multiple case study using semi-structured interviews and questionnaires conducted in late 2010 and early 2011. The reason for choosing the specific countries was due to the fact that the countries were part of the FoundryBench project within the Intelligent Energy Europe program.

Firstly, in collaboration with national foundry associations (led in the project by SwereaSWECAST) and research institutes in each country, a questionnaire was sent to 831 foundries, via e-mail or postal service. 125 foundries answered the questionnaire, 65 of which answered it completely. The complete study embraces several aspects regarding key features related to energy and production as well as barriers to increasing energy efficiency (as analysed by the authors in [47]), energy management practices and drivers for energy efficiency (reported in Table 1). For a more thorough presentation of the questionnaire, please see [47]. Inspired by the categorization provided in previous literature [37], the driving forces were divided into four different categories: financial, informational, organisational and external driving forces. In order to evaluate the answers, a Likert scale was established, ranging from 1 
to 5 as follows: no impact (1), almost no impact (2), impact (3), some impact (4), and major impact (5). For a more thorough description of the list of drivers, please refer to Table 1.

\section{Table 1}

We decided to perform additional interviews with the people responsible for energy issues at their site. The purpose of the interviews was twofold: on the one hand, to integrate the available information from the responses to the questionnaires, and on the other hand, to help clarify the

content of the responses. In preparing the interviews, a structured and fixed set of questions has been developed (presented in a fixed order), making it easy to both repeat ("replicate") the interview and compare the available information. Moreover, it should be noted that a fixed structure is crucial if the researcher can only meet the informant once, and hence the interview is not likely to be repeated. Finally, holding constant the order of questions helps to limit so-called context effects [54], for which the answers given to a survey may be dependent on the nature of preceding questions.

Through this combination of questionnaires and interviews we have built a multiple case study [55] among 65 European foundries (in Table 2 reporting the number of cases by country and firm size, according to the definition of SMEs given by the European Commission [56]).

\section{Table 2}

\section{Results}




\section{Energy saving potential}

The respondents in the study were asked to estimate energy saving potential in their foundries. In total, the respondents estimated an energy saving potential of $7.5 \%$. According to the European Commission in its 2020 Primary Energy roadmap, the energy efficiency potential for European industry is $25 \%$ where major improvements are stated to be found among the support processes according to the roadmap [57]. In regard to more energy-intensive industries like the foundry industry, it must be noted that the percentage of support processes is relatively lower than in non-energy intensive companies, due to a large use of energy in the production process $[52]$.

\subsection{Energy management practices}

According to Tanaka [58] identification of opportunities for improved energy efficiency is the most popular individual policy measure to improve industrial energy efficiency, followed by economic policies and prescriptive policies. Results from this multiple case study show that about two out of five foundries in the study have not conducted an energy audit, and foundries that had conducted an energy audit had higher energy use on average than the foundries that had not conducted an energy audit. Firms that have conducted an energy audit estimated lower energy efficiency potentials than foundries that have not conducted an energy audit. This might be related to the fact that after an energy audit, as shown by Cornelis [59], a company starts to adopt measures leading to lower potential a few years after the first audit.

Among the studied foundries, we observed a large discrepancy between countries, where three out of four of the German foundries had conducted an audit while in Italy, only one out of four foundries had conducted an energy audit. This could in turn be related to the respective nation's policy program towards the adoption of energy audits through subsidized energy audit programs. Germany, for example, has a history of energy audit programs [60]. When analysing 
these findings in relation to company size, results give a much more general picture: about half of the small, three out of five of the medium-sized, and two-thirds of the large foundries had conducted an energy audit. In conclusion, we can state that, starting from this exploratory analysis in the European foundry industry, energy audits, although widely recognized in the literature as a preferred means to increase the energy efficiency awareness of enterprises, thus providing useful information on inefficiencies and energy efficiency improvement opportunities, do not seem to be so much diffused yet. Indeed, European priorities towards a wider diffusion of energy audit in all sectors, and in particular within industry (with prescriptions for LEs and strong support for SMEs), seem to head for this important issue.

As can be seen in Fig. 1, about half of the studied foundries claim not to have a long-term energy strategy. This suggests lack of in-house energy management practices. This response is not endemically related to foundries. Thollander and Ottosson [7] found that a large part of the Swedish pulp and paper mills, nearly half, either lacked a long-term energy strategy or had a strategy less than three years. Results from a previous study of the Swedish foundry industry reveal similar findings as this study's; about half of the Swedish foundries lacked an energy strategy in 2007 [7].

\section{Fig. 1.}

It is noteworthy that the picture is quite dispersed. Indeed, in our sample of German enterprises, the lack of adoption of a long-term energy strategy seems to be limited to one out of four, whilst in Sweden about half of the companies responded that they have not implemented a long-term energy strategy. Similar to the result for whether they had conducted an energy audit or not, 
smaller firms seem to be less interested in adopting a long-term energy strategy (roughly one-third), compared with medium-sized (half) and large foundries (two-thirds).

Although acknowledging the limited sample of our preliminary analysis, we think it is possible to draw an interesting implication for policy-makers: future policies should emphasize the adoption of a long-term energy strategy, with particular attention to smaller enterprises. Indeed, this represents the first step to take energy efficiency more into the strategic arena in the company, e.g. investments in energy-efficient technologies (and, in particular, those related to specific production), that otherwise would face the risk of becoming neglected under strict investment criteria. As can be also seen in Fig. 1, only about one-fourth of the foundries in the study have employed performance-based energy services to implement energy efficiency measures, such as EPC. Indeed, EPC is widely "unknown" in general, and from our preliminary and explorative analysis of foundries in the investigated countries, we cannot detect a difference based on the size of the firm. In just a few cases, i.e., in German foundries, the picture is slightly different, as six out of sixteen adopt EPC. Hence, it is apparent that future work by policy-makers should be devoted in fostering the relationships between EPC providers (such as energy suppliers and/or ESCOs) and very small final users, that until now have been almost ignored. Finally, consulting an ESCO has been recognized as relevant, and able to realize about one-third of the energy saving potential.

\subsection{Driving forces to improve energy efficiency}

Fig. 2 shows the results from the responses related to the perceived driving forces for improved energy efficiency.

\section{Fig. 2.}


The primary drivers perceived as particularly critical are the threat of rising energy prices, cost reductions resulting from lowered energy use, commitment from top management, energy and emission taxes, people with real ambition, a long-term energy strategy, and international competition. In fact, in at least 50 out of the 65 investigated foundries, the above drivers have been evaluated as having some or even major impact on increasing the energy efficiency of enterprises.

In a first analysis by categories, the most relevant perceived driving forces are related to financial and organizational issues. Indeed, the most relevant (cost reductions, threat of rise in energy prices and energy taxes) are financially related, and right below them we may find organizational drivers (i.e., top management, people with real ambition). Finally, we can glimpse the existence of external driving forces, in particular thanks to the presence of the growing competition from the international context. This is reasonable considering the investigated sector, for which the so-called growing economies are increasing their relevance in the market. Moreover, alongside the already well-known and somehow expected external drivers (i.e., customer demand, demand from owner and obligations), we can see that the network within the sector is perceived as somehow having some impact.

Finally, we can note that information-related driving forces are not perceived as particularly relevant, as in the lowest positions we find drivers such as "public sector as a role model”, "your municipality being part of an energy/climate efficiency program" and "pressure from different environmental NGOs". Nonetheless, this result was partially expected as the investigated enterprises have participated in a European project aimed at raising the awareness of opportunities to reduce energy use and stimulating the spread of best practices for energy efficiency improvement in the foundry sector, and have been widely and directly contacted by 
local industrial organizations and groupings. Therefore, the presence of such actors seems to play a relevant role in lowering information-related barriers. We have then performed a preliminary, exploratory analysis of the driving forces with respect to some factors characterizing our sample (i.e., country and size of firm), as well as enterprises' adoption of the aforementioned energy management practices.

From a first look at the driving forces by size, we can note some interesting results that are worth commenting on. Firstly, the network along with the sector, as well as the information and support through the sector organization, are perceived as having much greater importance by smaller enterprises than larger ones. In fact, about eight out of ten smaller foundries believe those to be driving forces of importance, some with major impact. When larger firms are considered, those drivers seem to have less importance (in medium enterprises about five out of ten, and one out of three in larger ones). Secondly, small enterprises seem to perceive investment subsidies for energy efficiency technologies as having greater importance than medium and large enterprises. This seems to suggest that future European policies providing economic incentives should be carefully directed toward very small energy users.

In an analysis of driving forces by country, relevant differences cannot be detected, some exceptions being. Limiting our focus on the countries with the largest number of enterprises involved in the research, i.e., Sweden (20 enterprises) and Germany (16 enterprises), some interesting results can nonetheless be observed. Indeed, we can note that, the municipality being part of an energy or climate efficiency program is perceived as a relevant driver by 11 out of 20 foundries investigated, while one out of four in the total sample considered it as having some or major impact. Moreover, in Swedish cases, 17 out of 20 foundries consider the network within the sector as a relevant driver, compared with about $55 \%$ for the overall enterprises studied. Here Swedish foundries seem to have a different perception with respect to German ones, in which only one out of four believed the network within the sector to be a relevant driver. 
Looking at German enterprises, two comments appear relevant: for Beneficial loans for energy efficiency investments as well as for Investment subsidies for energy efficiency, technologies are perceived as much less relevant (respectively about one out of four and one out of three) with respect to the total sample of foundries investigated, which considered those driving forces as having some or major impact in about 6 out of 10 in both cases. At first glance, this difference can be attributed to the competitiveness of the German enterprises, and more generally, to the German economy relative to the rest of Europe.

Finally, by a first insight into driving forces with respect to energy management practices (Fig. 3), it is interesting to note how enterprises that have conducted an energy audit perceive such drivers.

\section{Fig. 3.}

Indeed, as can be read in Fig. 3, firms that have conducted an energy audit rank all the listed driving forces (by categories) higher than firms that have not conducted an energy audit. This can be particularly observed for information-related and organizational driving forces, presenting a difference of about half a point from each other. The results seems to suggest that, besides external and financial issues that should be promoted, the execution of an energy audit may preliminarily shed light on existing difficulties within an enterprise in implementing actions to improve energy efficiency. More clearly, having performed an energy audit seems to drive enterprises towards a greater awareness of what is effectively needed in order to shift towards more efficient, cleaner production [61], showing a greater need for information, management support, people with real ambition, etc. 


\section{Conclusion}

This paper presents the results from a multiple case study conducted in 2010-11 focused on drivers to energy efficiency improvements and energy management practices in the European foundry industry, research involving 65 foundries located in Finland, France, Germany, Italy, Poland, Spain and Sweden.

The investigation has shown that financially related driving forces, followed by organizational ones, are evaluated as the most relevant. By looking at financial drivers, the threat of rising prices as well as cost reductions resulting from lowered energy use are indeed perceived as the strongest driving forces towards more energy-efficient production. Considering the sample, made up of energy-intensive industries, the results show that energy efficiency has started to be perceived as a very promising field in which enterprises may increase their competitiveness, especially when facing international competition from economies with much lower labour costs, similar to what has already been observed in research in the broader field of eco-efficiency [62]. The study has also shown a great relevance of organizational driving forces such as commitment from top management and people with real ambition, showing that, in order to be effectively implemented, energy-efficient investments should become a priority on the agenda of company management.

Moreover, the study has given the opportunity to explore some characteristics of firms that should be taken into account when shaping energy efficiency policies. In fact, the firm's size has been shown to be important within SMEs as well: our study has shown that the network within the sector, as well as the information and support through the sector organization are perceived as particularly relevant in smaller enterprises, as confirmed in previous research 
within Italian SMEs for environmental issues [63]. To them, investment subsidies are also perceived as particularly important.

De Groot et al. (2001) found that the largest drivers in Dutch industry were cost reductions resulting from lowered energy use, followed by fiscal arrangements and investment subsidies [33]. [22] and [36] found that the largest drivers among Swedish foundries and non-energy intensive industry were long-term energy strategy and people with real ambition. When comparing these studies with ours, we find that the drivers are congruent.

Moreover, our study has given the opportunity to preliminarily highlight the relevance of some important energy management practices for the European foundry industry, i.e., adoption of energy audits, long-term energy strategy, and energy performance contracts.

Our paper moreover reveals that, despite a potential for improved energy efficiency using energy auditing, far from all the studied foundries have conducted an energy audit at their company. Relating this paper's findings to previous studies on the potential for energy efficiency improvements by energy management reveals similar challenges still to be overcome, e.g. low adoption of a long-term energy strategy indicates that there is still a large energy management gap to be bridged. Moreover, relating the findings to previous studies on energy services, e.g. [27-32], reveals similar findings; in order to improve energy efficiency there is an energy service gap still to be bridged: indeed, it seems that future efforts should be devoted in fostering the adoption of the existing instruments to promote energy efficiency and energy management within the foundry industrial sector, such as e.g. TPF and EPC, maybe thanks to a stricter support from ESCOs. The studied foundries estimate an energy saving potential in their own foundries of $7.5 \%$, an evaluation that is less than one third of what the EU Commission estimates for the whole European industry (25\%). Results moreover show that about two out of five foundries have not conducted an energy audit, and about half of the 
foundries in the study lack a long-term energy strategy. Moreover, the studied foundries estimate that approximately one-third of the energy saving potential could be tapped by employing performance-based energy services. Still only about one-fourth of the firms have used EPC.

Finally, the study's findings allow us to draw some interesting conclusions to be considered when designing and shaping future energy policies as well as for further research. Indeed, based on [10] and [52], Fig. 4 displays some major implications from the paper.

\section{Fig. 4.}

First and foremost, the low adoption of energy services in the studied foundries calls for the development of new business models, for example promoting EPC and TPF. However, this paper also shows that the use of energy audits and the adoption of energy management practices have large areas for improvement, as aforementioned. The implications for policy-making in this regard is that energy policies, e.g. energy audits and LTAs, should be more adequately designed to suit the foundry industry, which to a large degree consist of SMEs. The reason for the promotion of LTAs is that LTAs, unlike stand-alone energy audit programs, also involve management components in their policy design. Energy use expressed in its simplest form is Power multiplied by Time. While energy audit programs and energy services primarily involve the variable Power, energy management also involves the Time variable. As shown in Fig. 4, this implies, as previously stated by Backlund et al. [10] and Thollander and Palm [52], that the energy efficiency potential in terms of improved energy efficiency is in fact larger if management is also included. 
In order to support the development of the most effective energy efficiency policies, it seems interesting then to more deeply explore driving forces, thanks to a more thorough characterization, as well as an evaluation of the relationships between the external actions (e.g. incentives, taxes, regulatory issues, and information campaigns) and the effects within a single enterprise. In addition to that, it is important to analyse the capability of different external actors, e.g. local government or industrial associations, to stimulate drivers for energy efficiency. Moreover, it seems quite important to better characterize EEMs (both technologies and practices), understanding the full spectrum of their characteristics, benefits and possible implications, in terms of e.g. production disruption, increased productivity and working environment, emissions and waste reduction, and people responsible for their implementation, in order to understand the most suitable drivers to promote them. For both the characterization of drivers and EEMs, some preliminary contributions in the research can be found (respectively [64-65] and [66-67]), but further studies are needed.

As a final remark, we believe it is important to extend the research, in order to create a more detailed map of the adoption of energy management practices and the perceived driving forces from European enterprises to increase energy efficiency, also through other research methodologies that would enable a deeper statistical analysis of the results. Moreover, future work could explore the world of non-energy intensive enterprises, for which a higher relative energy-saving potential could be identified, and thus a lower implementation of energy management practices and energy-efficient technologies. Furthermore, it would be interesting to deepen the investigation within smaller users, representing the core of the industrial sector, and for which this preliminary study has found the lowest adoption of energy management practices. Indeed, this would enable the investigation towards which public policies could help to reduce the energy efficiency gap and increase energy efficiency in European foundry industries, and how they should be tailored according to the characteristics of these enterprises. 


\section{Acknowledgements}

The study has been carried out under the FoundryBench project financed by the European Commission within the Intelligent Energy Europe program. We kindly thank Lorenzo Giudici for his valuable contribution to this work. The authors also warmly thank the respondents at the studied foundries for giving freely of their time and attention to answer the questions, and the three anonymous reviewers for their good input and constructive suggestions. 


\section{References}

[1] IPCC, 2007. Contribution of Working Group III to the Fourth Assessment Report of the Intergovernmental Panel on Climate Change. Summary for Policymakers. Retrieved October 8, 2007, from: http://www.ipcc.ch/SPM0405 07.pdf

[2] Worrell, E., Laitner, J., Ruth, M., Finman, H., 2003. Productivity benefits of industrial energy efficiency measures. Energy 28(12): 1081-98.

[3] Hirst, E., Brown, M., A., 1990. Closing the efficiency gap: barriers to the efficient use of energy. Resources, Conservation and Recycling 3(4): 267-81.

[4] Pye, M., McKane, A., 2000. Making a stronger case for industrial energy efficiency by quantifying non-energy benefits. Resources, Conservation and Recycling 28(3-4): 171-183.

[5] Sorrell, S., Schleich, J., Scott, S., O’Malley, E., Trace, F., Boede, E., Ostertag, K. Radgen, P., 2000. Reducing Barriers to Energy Efficiency in Public and Private Organizations. Retrieved October 8, 2007, from: http://www.sussex. ac.uk/Units/spru/publications/reports/ barriers/final.html.

[6] Jaffe, A.B., Stavins, R.N., 1994. The energy efficiency gap: what does it mean? Energy Policy 22(10): 60-71.

[7] Thollander, P., Ottosson, M., 2010. Energy management practices in Swedish energy-intensive industries. Journal of Cleaner Production 18(12): 1125-1133.

[8] Thollander, P., Svensson I.L., Trygg L, 2010. Analyzing variables for district heating collaborations between energy utilities and industries. Energy 35(9): 3649-3656. 
[9] Rezessy, S., Bertoldi P., 2011. Voluntary agreements in the field of energy efficiency and emission reduction: Review and analysis of experiences in the European Union. Energy Policy 39: 7121-7129.

[10] Backlund, S., Thollander, P., 2011. The energy-service gap - What does it mean? In Proceedings of the European Council for an Energy Efficient Economy's Summer Study, 6-11 June, 2011.

[11] Klugman, S., Karlsson, M., Moshfegh, B., 2007. A Scandinavian chemical wood pulp mill. Part 1. Energy audit aiming at efficiency measures. Applied Energy 84(3): 326-39.

[12] Thollander, P., Karlsson, M., Söderström, M., Creutz, D., 2005. Reducing industrial energy costs through energy efficiency measures in a liberalized European electricity market—case study of a Swedish iron foundry. Applied Energy 81(2): 115-26

[13] Cagno E., Trucco P., Trianni A., Sala G., 2010. Quick-E-Scan: a methodology for the energy scan of SMEs, Energy 35(5): 1916-1926.

[14] Klugman, S., Karlsson, M., Moshfegh, B., 2009. A Swedish integrated pulp and paper mill-Energy optimization and local heat cooperation. Energy Policy 37(7): 2514-24.

[15] Cai, Y.P., Huang, G.H., Yang, Z.F., Tan, Q., 2009. Identification of optimal strategies for energy management systems planning under multiple uncertainties. Applied Energy 86(4): 480-95.

[16] Kissock, J.K., Eger, C., 2008. Measuring industrial energy savings. Applied Energy 85(5): 347-61.

[17] Costa, A., Paris, J., Towers, M., Browne, T., 2007. Economics of trigeneration in a kraft pulp mill for enhanced energy efficiency and reduced GHG emissions. Energy 32(4): 474-81. 
[18] Anderson, S.T., Newell, R.G., 2004. Information programs for technology adoption: the case of energy-efficiency audits. Resource and Energy Economics 26(1): 27-50.

[19] Harris, J., Anderson, J., Shafron, W., 2000. Investment in energy efficiency: a survey of Australian firms. Energy Policy 28(12): 867-876.

[20] Palm, J., and Thollander, P., 2010. Interdisciplinary perspective on industrial energy efficiency. Applied Energy 87(10): 3255-3261.

[21] Thollander, P., Ottosson, M., 2008. An energy efficient Swedish pulp and paper industry exploring barriers to and driving forces for cost-effective energy efficiency investments. Energy Efficiency 1(1): 21-34.

[22] Rohdin, P., Thollander, P., Solding, P., 2007. Barriers to and drivers for energy efficiency in the Swedish foundry industry. Energy Policy 35 (1): 672-677.

[23] Trianni A., Cagno E., 2012. Dealing with barriers to energy efficiency and SMEs: Some empirical evidences. Energy 37(1): 494-504.

[24] Christoffersen, L.B., Larsen, A., Togeby, M., 2006. Empirical analysis of energy management in Danish industry. Journal of Cleaner Production 14(5): 516-26.

[25] McKane, A., Williams, R., Perry, W., T, L., 2007. Setting the Standard for Industrial Energy Efficiency Retrieved, December 9, 2009, from: http://industrial-energy.lbl.gov/node/399

[26] Worrell, E., Bernstein, L., Roy, J., Price, L., Harnisch, J., 2009. Industrial energy efficiency and climate change mitigation. Energy Efficiency 2: 109-23.

[27] Hansen S., Langlois P., Bertoldi P., 2011, ESCOs Around the World. Lessons learned in 49 countries, The Fairmont Press, London. 
[28] Vine, E., 2003. International Survey of Energy Service Companies, unpublished, Lawrence Berkeley National Laboratory, Berkeley, CA.

[29] Vine, E., 2005. An international survey of the energy service company (ESCO) industry, Energy Policy 33: 691-704.

[30] Sorrell, S., 2007. The economics of energy service contracts, Energy Policy 2007 35: $507-21$.

[31] Backlund S., Thollander P., Palm, J., Ottosson, M., 2012, Extending the energy efficiency gap, Energy Policy 51: 392-396.

[32] Thollander, P., Ottosson, M., 2011. Energy related outsourcing - The case of ESCOs in the Swedish pulp and paper industry. In Proceedings of the IEEE International Technology Management Conference (ITMC), 27-39 June, 2011.

[33] de Groot_H., Verhoef, ET., Nijkamp, P., 2001. Energy saving by firms: decision-making, barriers and policies. Energy Economics 23: 717-740.

[34] Rohdin, P., Thollander, P., 2006. Barriers to and driving forces for energy efficiency in the non-energy intensive manufacturing industry in Sweden. Energy 31: 1836-1844.

[35] Thollander, P., Rohdin, P., Danestig, M., 2007. Energy policies for increased industrial energy efficiency: Evaluation of a local energy programme for manufacturing SMEs. Energy Policy 35 (11): 5774-5783.

[36] Hasanbeigi, A., Menke, C., du Pont, P., 2010. Barriers to energy efficiency improvement and decision-making behavior in Thai industry. Energy Efficiency 3(1): 33-52. 
[37] Cagno, E., Trianni, A., 2013. Exploring drivers for energy efficiency within small- and medium-sized enterprises: first evidences from Italian manufacturing enterprises. Applied Energy Vol. 104, April: 276-285.

[38] DeCanio, S., 1993. Barriers within firms to energy efficient investments. Energy Policy 9 (1): 906-914.

[39] DeCanio, S., 1998. The efficiency paradox: bureaucratic and organizational barriers to profitable energy-saving investments. Energy Policy 26 (5): 441-458.

[40] Fleiter, T., Worrell, E., Eichhammer W., 2011. Barriers to energy efficiency in industrial bottom-up energy demand models - A review. Renewable and Sustainable Energy Reviews 15: $3099-3111$.

[41] Cagno E., Worrell E., Trianni A., Pugliese G., 2013. A novel approach for barriers to industrial energy efficiency, Renewable and Sustainable Energy Reviews, Vol. 19, March: 290-304.

[42] Schleich, J., Gruber, E., 2008. Beyond case studies: Barriers to energy efficiency in commerce and the services sector. Energy Economics 30 (2): 449-464.

[43] Trianni, A., Cagno, E., Worrell, Pugliese, G., 2013. Empirical investigation of energy efficiency barriers in Italian manufacturing SMEs. Energy, 49 (1): 444-458.

[44] Nagesha, N., Balachandra, P., 2006. Barriers to energy efficiency in small industry clusters: Multi-criteria-based prioritization using the analytic hierarchy process. Energy 31 (12): 1969-1975. 
[45] Mukherjee, D. P., 2011. Barriers towards cleaner production for optimizing energy use and pollution control for foundry sector in Howrah, India. Clean Technologies and Environmental Policy 13 (1): 111-123.

[46] Li, Y., Chen, W., Huang, D., et al. 2010. Energy conservation and emissions reduction strategies in foundry industry. China Foundry 7 (4): 392-399.

[47] Trianni, A., Cagno, E., Thollander, P., Backlund, S., 2013. Barriers to industrial energy efficiency in foundries: a European comparison, Journal of Cleaner Production 40 (February): $161-176$.

[48] Nagesha, N., 2005. Energy Efficiency and Economic Performance in Small Scale Industry Clusters: An Analysis of Influencing Factors, Barriers and Drivers. Download at: http://hdl.handle.net/2005/1417

[49] Reddy, B.S., Assenza, G., 2007. Barriers and drivers to energy efficiency? A new taxonomical approach. Download at: http://ideas.repec.org.

[50] Cagno, E., Trianni, A., 2012. Analysis of the Most Effective Energy Efficiency Opportunities in Manufacturing Primary Metals, Plastics, and Textiles Small- and Medium-Sized Enterprises, ASME Journal of Energy Resources Technology, Vol. 134, No. 2 (June), 021005 (9 pages).

[51] Caffal, C., 1996. Energy Management in Industry. In: Analysis Series 17. Centre for the Analysis and Dissemination of Demonstrated Energy Technologies (CADDET), Sittard, The Netherlands.

[52] Thollander, P., Palm, J., 2012. Improving energy efficiency in industrial energy systems an interdisciplinary perspective on barriers, energy audits, energy management, policies \& programs. Springer. ISBN 978-1-4471-4161-7. 
[53] Lindgren Soroye, K., Nilsson, L.J., 2010, Building a business to close the efficiency gap: The Swedish ESCO experience, Energy Efficiency 3: 237-56.

[54] Patton, M., 1990. Qualitative evaluation and research methods, 2nd ed. Newbury Park, CA: Sage.

[55] Yin, R. K., 2003. Case Study Research: Design and Method. Applied Social Research Methods, 3rd ed.. London: Sage.

[56] European Council, Commission Recommendation of 6 May 2003 concerning the definition of micro, small and medium-sized enterprises. Official Journal of the European Union, 6.

[57] EC (European Commission), 2006. Communication from the Commission. Action Plan for Energy Efficiency: Realising the Potential. COM(2006)545 final.

[58] Tanaka, K., 2011. Review of policies and measures for energy efficiency in industry sector. Energy Policy 39(10): 6532-6550.

[59] Cornelis, E., Reunes, G., 2012. Analysis of the differences of the energy saving measures proposed by medium-sized industrial companies in Flanders, Belgium in 2006 and 2009. In ECEEE 2012 Industry Summer Study.

[60] Gruber, E., Brand, M., 1991. Promoting energy conservation in small and medium-sized companies. Energy Policy 19 (3): 279-287.

[61] Cagno, E., Micheli, G.J.L., Trucco, P., 2012. Eco-efficiency for sustainable manufacturing: An extended environmental costing method, Production Planning \& Control: The Management of Operations 23(2-3): 134-144. 
[62] Cagno, E., Trucco, P., Tardini, L., 2005. Cleaner production and profitability: Analysis of 134 industrial pollution prevention (P2) project reports, Journal of Cleaner Production 13(6): 593-605.

[63] Cagno, E., Trucco, P., 2008. Cleaner technology transfer in the Italian galvanic industry: economic and know-how issues, Journal of Cleaner Production 16(1): 32-36.

[64] Trianni, A., Cagno, E., Marchesani, F., Spallina, G., 2013. Drivers for industrial energy efficiency: An innovative approach, Proceedings of the 5th International Conference on Applied Energy (ICAE 2013), 1-4 July, Pretoria (ZA).

[65] Cagno, E., Trianni, A., Spallina, G., Marchesani, F., 2013. Drivers for industrial energy efficiency: Pieces of evidence from Italian manufacturing enterprises, Proceedings of the 5th International Conference on Applied Energy (ICAE 2013), 1-4 July, Pretoria (ZA).

[66] Trianni, A., Cagno, E., De Donatis, A., 2013. Characterizing industrial energy efficiency measures, Proceedings of the 5th International Conference on Applied Energy (ICAE 2013), 1-4 July, Pretoria (ZA).

[67] Cagno, E., Trianni, A., 2013. Evaluating barriers to cross-cutting energy-efficient technologies in Italian SMEs: An empirical evaluation, Proceedings of the 5th International Conference on Applied Energy (ICAE 2013), 1-4 July, Pretoria (ZA). 


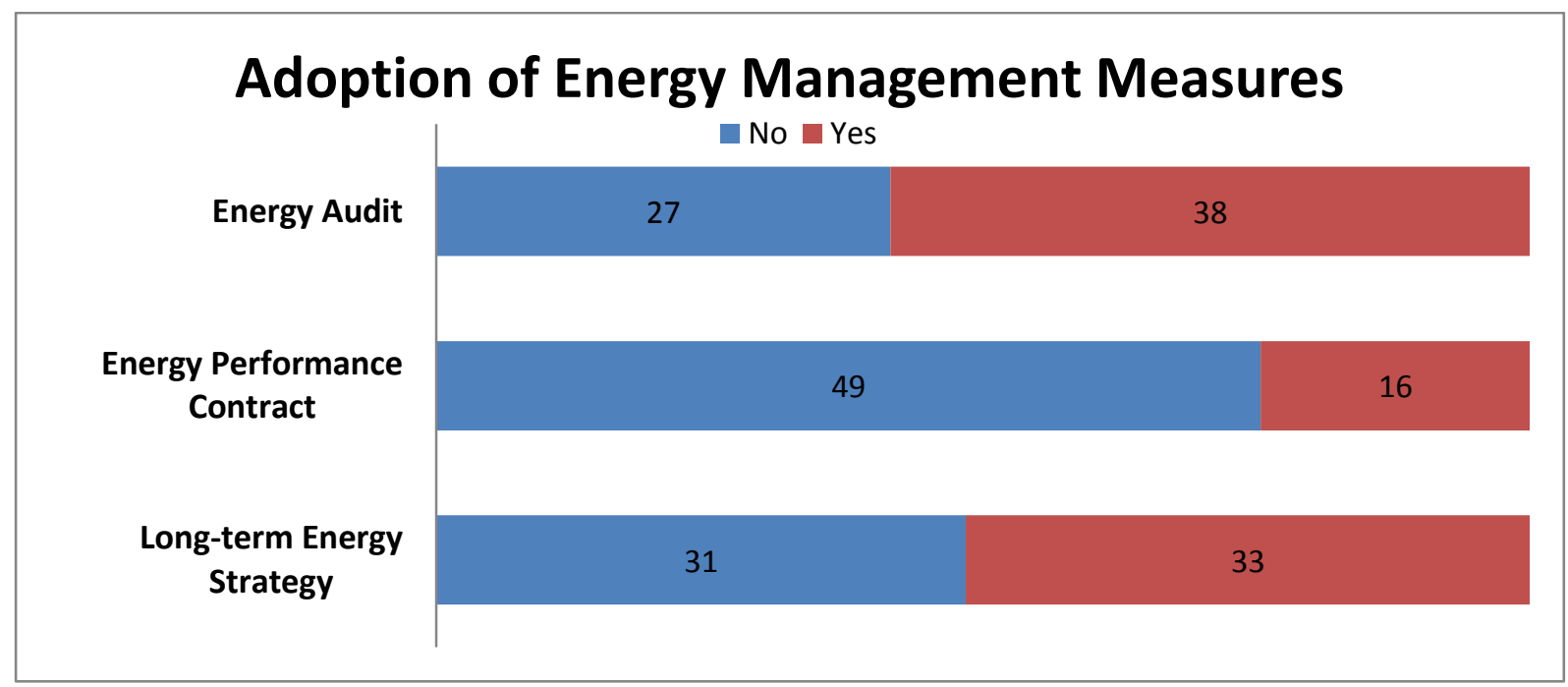

Fig. 1. Adoption of energy management measures in the investigated sample of European foundries. 


\section{Driving forces for energy efficiency}

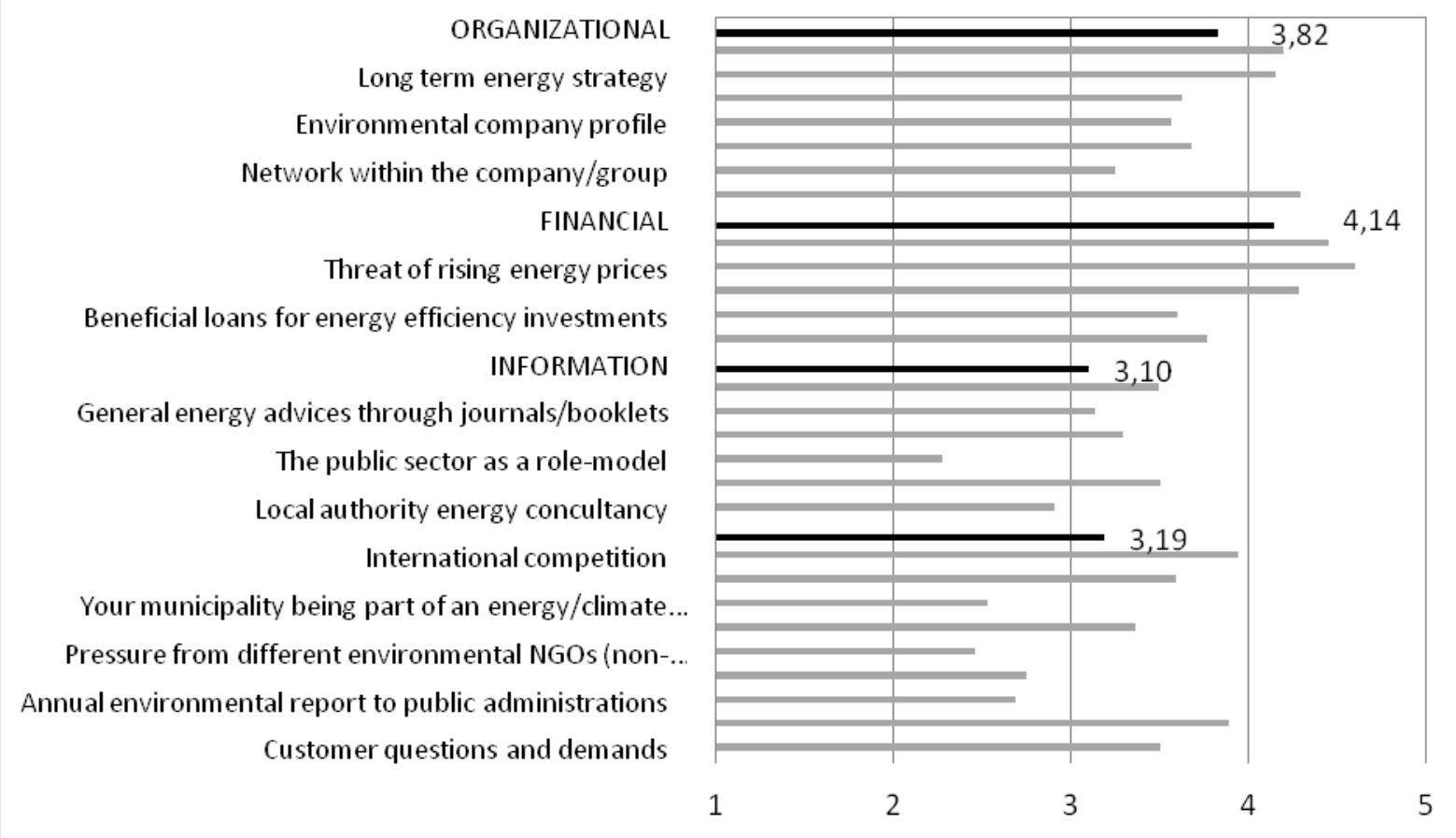

Fig. 2. Total ranking of driving forces among the studied foundries evaluated through a Likert scale from 1 "no impact" to 5 "major impact". 


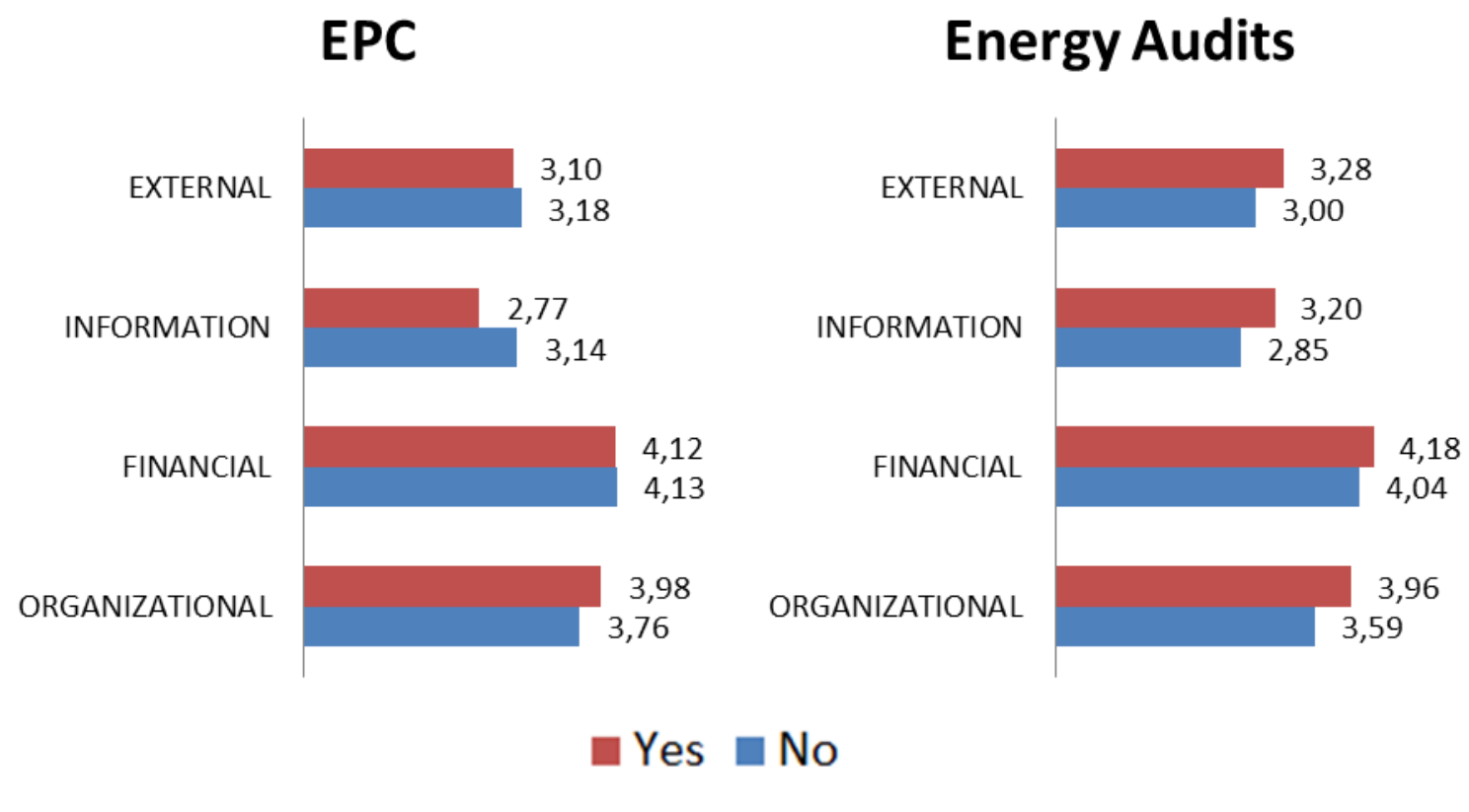

Fig. 3. Comparison of driving forces between foundries that have used EPC or conducted an energy audit or not. 


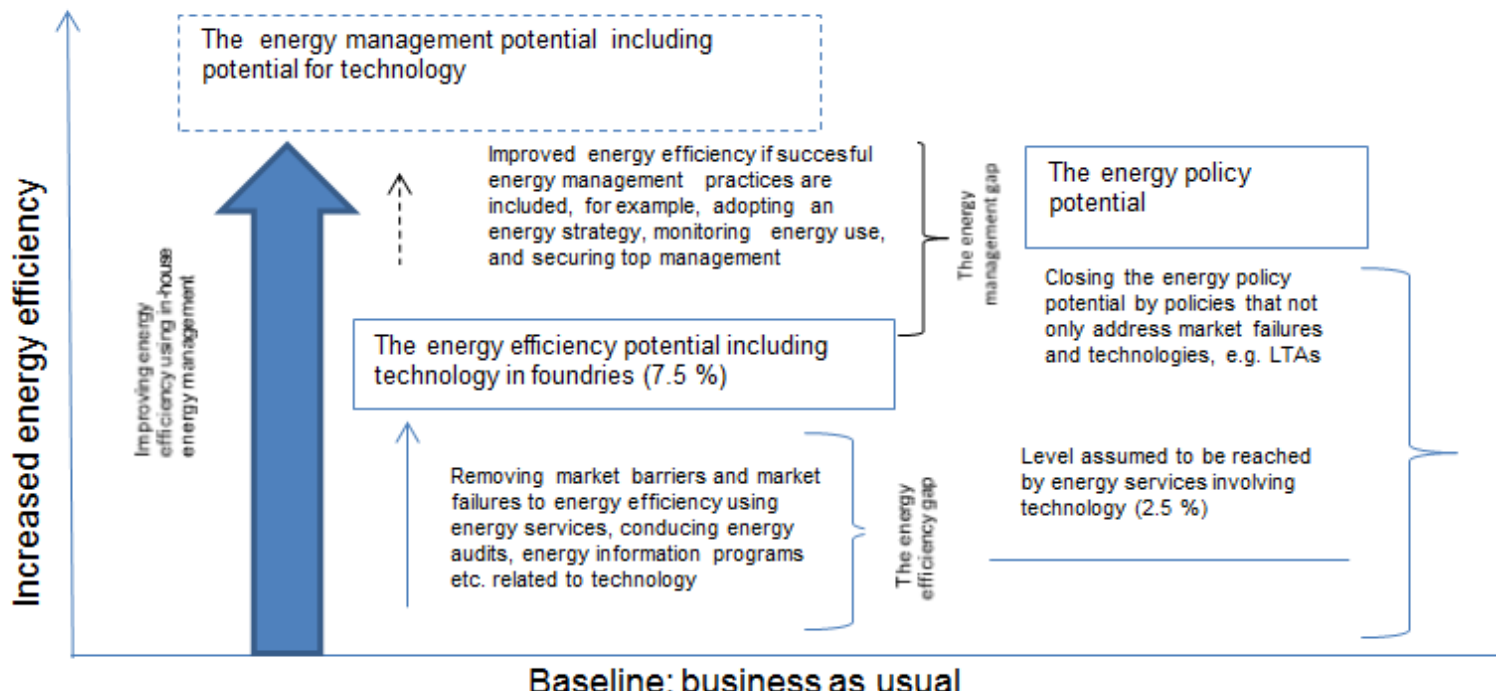

Fig. 4. Energy policy implications when energy-efficient technology, energy services, and energy management are included (based on [52]). 


\section{Table 1}

Driving forces for increased energy efficiency implementation

\begin{tabular}{|c|c|}
\hline \multirow[t]{5}{*}{ Financial driving forces } & Energy taxes including taxes on Sulphur, Nox and CO2 \\
\hline & Threat of rising energy prices \\
\hline & Cost reductions from lowered energy use \\
\hline & Beneficial loans for energy efficiency investments \\
\hline & Investment subsidies for energy efficiency technologies \\
\hline \multirow[t]{6}{*}{ Informational driving forces } & Local public energy consultants \\
\hline & Public sector as a role model \\
\hline & Voluntary agreements \\
\hline & Energy advice through journal/booklets \\
\hline & Energy advice through seminars \\
\hline & Information and support through sector organization \\
\hline \multirow[t]{5}{*}{ Organizational driving forces } & Commitment from top management \\
\hline & Network within the company \\
\hline & Improve working conditions \\
\hline & Company's environmental profile \\
\hline & Environmental management system \\
\hline
\end{tabular}




\begin{tabular}{|c|c|}
\hline & Long-term energy strategy \\
\hline & People with real ambition \\
\hline \multirow[t]{9}{*}{ External driving forces } & Demand from customers \\
\hline & Demand from owner \\
\hline & Annual environmental report to public administrations \\
\hline & Pressure from environmental NGOs \\
\hline & Network within the sector \\
\hline & $\begin{array}{l}\text { Your municipality being part of a climate/energy } \\
\text { efficiency programme }\end{array}$ \\
\hline & National requirements for energy efficiency \\
\hline & International competition \\
\hline & $\begin{array}{l}\text { ESCOs responsible for operation and maintenance of the } \\
\text { buildings }\end{array}$ \\
\hline
\end{tabular}


Table 2

Overview of enterprises involved in the research from the FoundryBench project. SE: Small Enterprise (10-49 employees); ME: Medium-sized Enterprise (50-249 employees); LE: Large Enterprise (>250 employees).

\begin{tabular}{|c|c|c|c|}
\hline \multirow[t]{2}{*}{ Country } & \multicolumn{3}{|c|}{ Company size } \\
\hline & $\overline{\mathrm{SE}}$ & ME & $\mathbf{L E}$ \\
\hline Finland & 3 & 0 & 1 \\
\hline France & 4 & 3 & 3 \\
\hline Germany & 1 & 8 & 7 \\
\hline Italy & 1 & 1 & 2 \\
\hline Poland & 2 & 2 & 2 \\
\hline Spain & 2 & 3 & 0 \\
\hline Sweden & 17 & 3 & 0 \\
\hline Total & 30 & 20 & 15 \\
\hline
\end{tabular}

